\title{
O ESTATUTO DO CONSUMO NA COMPREENSÃO DA LÓGICA E DAS MUTAÇÕES DO CAPITALISMO
}

Isleide Arruda Fontenelle

O sentimento do consumidor e a confiança do consumidor nas sociedades mais afluentes não são apenas as chaves para a acumulação do capital sem fim, mas são também cada vez mais a base da qual depende a sobrevivência do capitalismo. (HARVEY, 2010B, P. 92) ${ }^{1}$

Foi como fenômeno histórico que o consumo interessou inicialmente o campo da teoria social. A partir da década de 1960, diante de sociedades ocidentais já impregnadas de objetos para consumo, autores começaram a se dar conta de que seria necessário entender esse fenômeno. Essas análises surgem sob o ponto de vista de teóricos associados à teoria crítica, como Theodor Adorno, Max Horkheimer, Herbert Marcuse, George Luckács, entre outros, focados em entender uma cultura já impregnada pela forma-mercadoria e, portanto, por processos de alienação, reificação e fetichização. Na década de 1970, surge o livro de Jean Baudrillard

\footnotetext{
${ }^{1}$ Todas as traduções de trechos incluídos neste artigo foram feitas pela autora.
} 
(1998 [1970]), The consumer society: myths and structures, que procurou ir além da perspectiva marxista, focando mais na lógica social e simbólica do consumo, mas ainda tomando-o como espaço oriundo da centralidade da produção capitalista de mercadorias.

Agora, sabemos que esses autores discorriam sobre o lugar do consumo resultante das décadas douradas do capitalismo (1945-75), aquela marcada "por um excepcional crescimento econômico, pela elevação do nível de produtividade do trabalho e pela extensão da regulação fordista da economia. Multiplicando por três ou quatro o poder de compra dos salários, democratizando os sonhos do Eldorado consumista, [esse período] apresenta-se como o modelo puro da sociedade do consumo de massa" (Lipovetsky, 2007, p. 32).

A partir do final da década de 1970 e nas duas décadas seguintes, já estava em ebulição uma reestruturação 208 produtiva radical que alteraria igualmente o campo do consumo. A percepção e vivência dessa realidade por aqueles que escreviam nesse período levou ao surgimento de um campo de análises próprias ao consumo, que passou a tomá-lo como central na compreensão da sociedade e cultura contemporâneas; mas, desta vez, tomando-o como uma esfera autônoma não derivada inequivocamente da produção capitalista, assim como um fenômeno moderno que pode, inclusive, ter precedido a Revolução Industrial (cf. McKendrick, Brewer e Plumb, 1983; Slater, 1997; Featherstone, 1987, 1990; Miller, 2013; Campbell, 2001, entre outros).

No contexto da teoria marxista, autores contemporâneos como Fredric Jameson (1991, 1993) e André Gorz (2005) também buscaram entender a centralidade do consumo e sua nova lógica no funcionamento do capitalismo, que já começara a ser compreendido como um "capitalismo de consumo". Dessa perspectiva, o consumo continuou sendo 
visto como resultante da produção capitalista e seu processo de mercantilização ${ }^{2}$.

Este artigo pretende operar a partir de um ponto de vista que considere essas duas perspectivas: por um lado, concorda que o consumo, pensado no sentido preciso do "uso das coisas", de fato, é anterior ao modelo capitalista de produção e pode até mesmo coexistir com este, quando ainda não impregnado pela lógica da mercadoria. Por outro lado, considera que os objetos não são consumidos da mesma forma sob o capitalismo. Nesse modo de produção, eles ganham um status próprio de mercadoria e isso altera profundamente a relação entre consumidores e objetos, conforme se pretende mostrar ao longo deste texto. É, portanto, da perspectiva do consumo no contexto de uma sociedade capitalista que este artigo tratará.

Segundo o filósofo esloveno Slavoj Žižek (2008), os teóricos marxistas que buscaram uma interpretação do consumo, sob o capitalismo, caíram no erro comum de classificarem a esfera do consumo como ilusória, em contraposição à esfera "real" da produção e do trabalho. Ao partirem dessa interpretação, diz Žižek, esses sofisticados teóricos do fetichismo da mercadoria - desde o jovem Georg Lukács até Fredric Jameson, passando por Theodor Adorno - caíram em uma armadilha comum:

\footnotetext{
${ }^{2}$ Embora não seja possível localizar o sociólogo Zygmunt Bauman no contexto dos teóricos marxistas strictu senso, há que se admitir que suas observações não perdem de vista o caráter concreto de uma análise do consumo no interior do capitalismo, uma vez que ele parte do fato de que esse tipo de consumo é produto de uma forma de produção específica, qual seja, o modo de produção capitalista. Bauman é um dos mais prolíferos analistas sociais contemporâneos focados no consumo (cf. Bauman, 2010). Por outro lado, autores de tradição marxista, como Antonio Negri (1989), Paolo Virno (2004) e Maurizio Lazzarato (2006), trazem contribuições importantes sobre a lógica e os desafios contemporâneos da realização do valor que, embora não caracterizem estudos específicos do campo do consumo, apontam para contradições dessa esfera diante das transformações atuais do capitalismo, como veremos adiante.
} 
[...] a maneira como explicam a falta de movimento revolucionário é dizendo que a consciência dos trabalhadores é turvada pela sedução da sociedade consumista e/ou pela manipulação das forças ideológicas de hegemonia cultural, e é por isso que o foco da obra crítica deveria passar para a "crítica cultural" que mantém os trabalhadores sob o feitiço da ideologia burguesa (Žižek, 2008, p. 75).

O que Žižek pretende marcar com essa crítica é a ideia de que a natureza mesma do capitalismo se funda em uma ilusão. E que, portanto, tanto o campo da produção como o do consumo operam em conjunto para fazer essa ilusão do capitalismo funcionar. Tal proposição, por sua vez, repousa nas análises de Marx sobre aquilo que constitui a essência do capitalismo: a produção do excedente de capital e sua expansão infinita na esfera da circulação. Sem 210 isso, sem a circulação de dinheiro como capital, não existe capitalismo. E por que assumir que tal movimento tem uma natureza ilusória?

Para explicitar tal afirmação, Žižek retoma a descrição clássica de Marx da passagem de dinheiro a capital. Inicia com a famosa afirmação marxiana de que a circulação simples de mercadoria - o ato de vender para comprar - tem por objetivo a satisfação das necessidades sociais, portanto, tem uma finalidade fora da circulação. Com o surgimento do capital, essa circulação simples dá lugar a outra lógica: é preciso investir dinheiro em alguma mercadoria para vendê-la de novo a fim de receber mais dinheiro e, com isso, eternizar a circulação, já que, diz Marx, a circulação de dinheiro como capital "tem sua finalidade em si mesma, pois a expansão do valor só existe nesse movimento continuamente renovado. Por isso o movimento do capital não tem limites" (Marx, 1992, p. 171; Žižek, 2008, pp. 85-86). 
Assim que a circulação do capital se põe em movimento, "a verdadeira meta não é mais a satisfação de necessidades individuais, mas simplesmente mais dinheiro" (Žižek, 2008, pp. 87-88). Essa é a verdade do capitalismo, a busca da circulação infinita. Ao mesmo tempo, essa verdade é constituída a partir de uma ilusão, qual seja, de que esse movimento circular engendra a si mesmo. Esse é o engodo objetivo do capital, diz Žižek, já que o capitalismo não pode engendrar a si mesmo: "na realidade, o capitalismo não engendra a si mesmo, mas explora a mais-valia do trabalhador" (Žižek, 2008, p. 88; grifo meu). E não apenas isso, ou seja, a realidade do capitalismo não se resume à mais-valia obtida na esfera da produção, pois o mais-valor que o capitalismo necessita para se expandir continuamente só pode se realizar como tal na esfera da troca, só se efetiva com o consumo. Esse movimento dialético entre produção, consumo e realização do valor, será detalhado na primeira parte deste artigo, quando será demonstrada a importância que o consumo tem no processo mesmo de estruturação do capitalismo como um sistema de produção e realização de valor.

Se em uma análise objetiva do processo capitalista é possível ver como sua verdade se apoia em uma ilusão, é preciso entender como o consumo funciona como o grande organizador social da ilusão, pelo menos, desde a Revolução Industrial, quando foram desenvolvidas diferentes estratégias de mercado para que fosse moldada uma cultura movida pelo desejo de consumir. Foi necessário produzir formas de vida para que se perpetuasse a circulação do excedente, o que ocorreu mediante a produção de uma cultura do consumo. A segunda parte deste artigo remete à história da produção de uma sociedade culturalmente forjada pela lógica do consumo de mercadorias já em fins do século XIX, e que tem perdurado, com diferentes nuances, até os dias atuais. Neste quesito, o artigo dialoga com uma produção sociológica sobre o consumo como campo de 
estudo próprio, a fim de determinar qual a diferença que se estabelece no uso das coisas quando essas são transformadas em mercadorias.

As transformações recentes do capitalismo e seus impactos nas esferas da produção e do consumo, porém, não teriam tornado a leitura marxiana obsoleta? Afinal, Marx analisou o capitalismo industrial do século XIX. O que restaria de sua análise para a compreensão das novas formas que assume o capitalismo contemporâneo? Onde se localiza o consumo nas formas que assumiu o capitalismo financeiro e o capitalismo imaterial em fins do século XX? Ver-se-á, na terceira parte deste artigo, que esses novos formatos podem ser compreendidos pela maneira como eles se utilizam do consumo para a realização do valor. Ver-se-á, portanto, que uma análise do capitalismo contemporâneo, com base em Marx, ainda é fundamental, desde que as análises marxianas não sejam reduzidas ao caráter

212 puramente contingente do capitalismo industrial e do seu "chão de fábrica", mas a partir da sua lógica estrutural, que permanece constante e atual, qual seja, a busca da expansão do valor.

Este artigo propõe um retorno à Marx fazendo uso do pensamento dialético, a fim de capturar a fluidez, a mutabilidade, assim como as contradições próprias ao capitalismo. Segundo o geógrafo David Harvey, a forma como Marx analisa o capitalismo não é a partir de uma configuração estrutural, estática, como foi lido por muitos. Pelo contrário, Marx soube captar o essencial do capitalismo: que ele não é nada se não estiver em movimento. Harvey lembra que alguns

[...] gostam de pensar que a dialética diz respeito exclusivamente a tese, antítese e síntese, mas o que Marx diz é que não existe síntese. O que existe é apenas a internalização da contradição e sua acomodação num grau 
mais elevado. As contradições nunca são definitivamente resolvidas [...] No entanto, há momentos aparentes de resolução (Harvey, 2010a, p. 68).

A assunção da lógica do capitalismo como movimento e o pensamento dialético como recurso para a compreensão dessa lógica são as bases metodológicas deste artigo. Tais bases permitem que se entenda o consumo como central no interior mesmo da análise do modo de produção capitalista feita por Marx (e não apenas a partir da década de 1970 e do consequente esgotamento do capitalismo industrial, como tem sido frequentemente interpretado); que se explicite como ele tornou o grande organizador social da ilusão no capitalismo; e que se compreenda, finalmente, o quanto esse "momento aparente de resolução" através do consumo, que já perdura por, pelo menos, um século, encontra-se, hoje, diante de alguns desafios que revelam impasses do próprio capitalismo.

\section{Um retorno a Marx: o lugar do consumo na ilusão do capital}

Se as mercadorias pudessem falar, diriam: é possível que nosso valor de uso tenha algum interesse para os homens. A nós, como coisas, ele não nos diz respeito. O que nos diz respeito materialmente é nosso valor. (MARX, 1992, P. 157)

Pode-se afirmar que no Livro I d $O$ capital - o único realmente concluído pelo autor -, Marx tem por objetivo principal analisar o modo de produção capitalista do ponto de vista exclusivo da produção. Mas o modo como o autor entendeu e representou o funcionamento do capitalismo é essencial para que se explicite o argumento proposto neste artigo. Em $O$ capital, o autor parte do princípio de que 
o capitalismo é um modo de produção de mercadorias e que a mercadoria contém um duplo valor: valor de uso e valor de troca. $\mathrm{O}$ valor de troca é inicialmente apresentado por Marx como "o modo necessário de expressão ou forma de manifestação do valor” (Marx, 1992, p. 116). A questão fundamental para Marx, portanto, é mostrar o que é esse valor contido na mercadoria. Para isso, Marx constrói a argumentação partindo do mais básico: o valor de uso: "A utilidade de uma coisa faz dela um valor de uso" (p. 114), ao passo que "o valor de troca aparece inicialmente como a relação quantitativa, a proporção na qual valores de uso de um tipo são trocados por valores de uso de outro tipo, uma relação que se altera constantemente no tempo e no espaço" (p. 114). Marx ainda afirma que "o valor de uso se efetiva apenas no uso ou no consumo" (p. 114; grifos meus) e, que, portanto, o valor de uso constitui o suporte material do valor de troca. Porém, "nega que a materialidade 214 das mercadorias seja capaz de nos dizer alguma coisa sobre aquilo que as torna comensuráveis" (Harvey, 2010a, p.27). Se abstrairmos o valor de uso do corpo das mercadorias, diz Marx, "resta nelas uma única propriedade: a de serem produtos do trabalho" (Marx, 1992, p. 116). Entretanto, não se trata de trabalho concreto (tempo efetivo despendido no trabalho), mas sim de trabalho humano abstrato: "uma objetividade fantasmática, uma simples geleia de trabalho humano indiferenciado, i.e., de dispêndio de força de trabalho humana ${ }^{3}$, sem consideração pela forma de seu dispêndio" (Marx, 1992, p. 116). O ponto de chegada dessa

\footnotetext{
${ }^{3}$ É interessante e didática a maneira como David Harvey interpreta, aqui, a teoria do valor de Marx. Diz ele: "para compreender o que significa esse 'dispêndio da mesma força de trabalho humana', é preciso olhar para a 'força de trabalho conjunta da sociedade', o que significa invocar tacitamente um mercado mundial que foi introduzido pelo modo de produção capitalista [...] a medida do valor é derivada desse mundo inteiro de trabalho humano [...] É nesse terreno global dinâmico de relações de troca que o valor é determinado e redeterminado continuamente" (Harvey, 2010a, p. 29; grifos meus).
} 
configuração permite, então, que se reinterprete o valor de troca como "uma representação necessária do trabalho humano incorporado nas mercadorias" (Harvey, 2010a, p. 28). O trabalho humano incorporado nas mercadorias sob a forma de trabalho abstrato - é, por sua vez, gerador de valor.

É nesse ponto que a questão do consumo deve ser colocada, pois, ao avançar em sua análise, Marx formula uma definição de valor como "tempo de trabalho socialmente necessário, aquele requerido para produzir um valor de uso qualquer sob as condições normais para dada sociedade e com o grau social médio de destreza e intensidade do trabalho" (Marx, 1992, p. 117). Com tal definição de valor, Marx envereda por uma longa análise sobre a relação entre a grandeza de valor de uma mercadoria e o tempo de trabalho requerido para a sua produção. Mas o que interessa, para os propósitos deste artigo, é a maneira como essa definição de valor permite que se recupere a importância do valor de uso no contexto da produção de mercadorias e, por essa via, se explicite também a importância do consumo para a realização do valor. Marx afirma que, para produzir mercadoria, é necessário que se produza

[...] não apenas valor de uso, mas valor de uso para outrem, valor de uso social [...] Para se tornar mercadoria, é preciso que o produto, por meio da troca, seja transferido a outrem, a quem vai servir como valor de uso $[. .$.$] nenhuma coisa$ pode ser valor sem ser objeto de uso. Se ela é inútil, também o é o trabalho nela contido, não conta como trabalho e não cria, por isso, nenhum valor (Marx, 1992, p. 119).

Como posto inicialmente, Marx afirma que é no uso ou no consumo que o valor de uso se concretiza. Como bem desenvolvido por Harvey, em um livro escrito justamente "para entender $O$ capital", "o valor de uso é socialmente necessário 
para o valor" pois, "se a mercadoria não satisfaz uma carência, um desejo ou uma necessidade humana, ela não tem valor nenhum! Em suma, você tem de poder vendê-la para alguém em algum lugar" (Harvey, 2010a, p. 32; grifos meus). Desse seu argumento, Harvey tece reflexões importantes sobre a intricada teia que envolve valor de uso, valor de troca e valor, demonstrando a impossibilidade de separarmos algum desses conceitos sem nos referirmos aos demais, pois

[...] não podemos dividir a mercadoria ao meio e dizer que uma parte é o valor de troca e a outra é o valor de uso. Não, a mercadoria é uma unidade. Mas dentro dessa unidade há um aspecto dual, e esse aspecto dual nos permite definir algo chamado valor como tempo de trabalho socialmente necessário, e é a este último que o valor de uso de uma mercadoria serve de suporte ${ }^{4}$. Mas para ter valor, a mercadoria tem de ser útil (Harvey, 2010a, p. 33).

O "salto mortal" da mercadoria, portanto, ocorre no momento em que ela deve se realizar no consumo. E, tendo em vista a lógica da expansão do capital, essa realização precisa ocorrer no menor tempo possível, diminuindo, portanto, a lacuna temporal entre a criação e a realização do valor.

Parafraseando Harvey, Marx conseguiu construir, com seu modo de análise, um caminho convincente de entendimento do nexo frágil e problemático entre o valor (o tempo de trabalho socialmente necessário incorporado nas mercadorias) e a sua realização pelo consumo. Não por acaso, no

\footnotetext{
${ }^{4}$ Novamente, aqui, as explanações complementares de Harvey são importantes para a compreensão do consumo como organizador social da ilusão. Segundo ele, o conceito de trabalho socialmente necessário coloca questões importantes: "o que é socialmente necessário? Como isso é estabelecido e por quem? Quais são as necessidades sociais embutidas no modo de produção capitalista? O que Marx diz é que há certo tipo e medida de valor que é determinado por um processo que não compreendemos e que não depende necessariamente de uma escolha consciente" (Harvey, 2010a, p. 30; grifos meus).
} 
Livro II d $O$ capital, publicado originalmente em 1885, Marx se volta para a circulação do capital nos negócios e na sociedade, tentando "detalhar um sistema sempre em expansão que criava mercados onde antes não existia mercado, apenas para descarregar produtos destinados a consumidores que não precisavam deles e que não os haviam solicitado" (Gabriel, 2013, p. 689). É para a esfera do consumo - e de sua dinâmica - que nos movemos agora.

\section{A produção da cultura de consumo como organização social da ilusão}

Talvez a mercadoria seja produto de um novo modo de trabalho, que se destina à satisfação de uma necessidade recém-surgida ou pretende ela própria engendrar uma nova necessidade. (MARX, 1992, P. 180)

Afirmar que o consumo é o organizador social da ilusão é assumir que é pelo consumo que a "verdade ilusória" do capitalismo vem se sustentado, pelo menos, desde a Revolução Industrial, entendida como "a criação de um sistema fabril mecanizado que por sua vez produz em quantidades tão grandes e a um custo tão rapidamente decrescente a ponto de não mais depender da demanda existente, mas de criar o seu próprio mercado" (Hobsbawm, 2006, p. 64). É dessa forma que o historiador inglês Eric Hobsbawm esclarece a epígrafe de Marx. Como exemplo, o autor lembra que não foi a demanda por carros em 1890 que criou a indústria automobilística, mas foi a capacidade de produzir carros baratos que levou à produção de uma demanda social por automóveis, que formatou um estilo de vida do qual a época atual ainda é herdeira.

É nesse ponto que surgem as divergências entre os autores marxistas e aqueles que buscaram compreender as relações 
sociais a partir do consumo de uma perspectiva que não seja derivada diretamente da produção. Os sociólogos Don Slater (1997) e Mike Featherstone (1987, 1990), por exemplo, analisam a cultura de consumo como um fenômeno indissociável da modernidade e seu valor maior, o progresso. $\mathrm{O}$ antropólogo Daniel Miller (2013) faz uma defesa da cultura material para além das sociedades capitalistas de consumo e argumenta, com base em pesquisas etnográficas realizadas em diferentes culturas, que as sociedades não industriais também são movidas por desejos de consumo. O sociólogo Colin Campbell (2001) procurou entender qual "espírito de época" estava presente no período que antecedeu e precedeu a Revolução Industrial. Em sua análise, o autor localiza duas éticas andando concomitantemente e que favoreceriam a emergência de uma cultura de consumo capitalista: uma ética protestante, fartamente referendada nas análises de Max Weber (2004) em A ética protestante e o espirito do capitalismo, e 218 uma ética romântica, baseada no hedonismo. Na tese defendida por Campbell, a burguesia abraçou tanto a ética protestante como a ética romântica, para forjar uma ética do consumo. Mas essa metamorfose, de "hedonismo romântico" em consumo, não ocorreu de forma imediata. A ressignificação desse "espírito de época" em uma cultura de consumo foi um longo processo que ocorreria a partir dos desdobramentos da Revolução Industrial e dos rumos próprios da cultura que se forjava. Em outras palavras, não estava determinado que a ética romântica se desdobraria em uma ética do consumo. Por isso mesmo, Campbell (2001, pp. 289-90) afirma que

[...] nem os primeiros românticos, nem seus sucessores nas décadas subsequentes, tencionaram jamais conferir legitimidade ao consumismo moderno ou a esse espírito de hedonismo egoísta em que se baseou. Nem, na verdade, procuraram eles agir no sentido de superar as objeções tradicionais à procura do prazer meramente 
para permitir a exploração comercial de novos setores de interesse hedonista.

Algo que a história viu se repetir com o movimento contracultural de fins da década de 1960, quando a crítica ao capitalismo passou a ser incorporada pelo próprio capitalismo no forjar de uma cultura de consumo que se nutria da própria crítica (cf. Boltanski e Chiapelo, 2009; Frank, 1997).

Sem dúvida, esses autores apresentam leituras sobre a relação dos homens com os objetos que não podem ser descartadas. Pelo contrário, elas são fundamentais para a compreensão de que o capitalismo precisou lançar mão de certo espírito de época (a modernidade, o romantismo), e de toda uma cultura material que lhe é anterior, a fim de criar uma cultura de consumo conduzida pela lógica própria do capital.

Como já visto, o valor de uso só se realiza no uso ou no consumo, portanto, o valor de uso é socialmente necessário para o valor. Se às mercadorias só interessam seu valor de troca, ao consumidor é necessário que se apele para o valor de uso da mercadoria, momento no qual há uma recuperação do sentido do objeto e do uso das coisas, porém, de forma já ressignificada pela necessidade do capital. E é aqui onde está a grande diferença de se pensar o consumo em uma sociedade capitalista: os objetos precisam ser consumidos como mercadorias, por isso, passam a ter uma espécie de valor de uso de segunda natureza, ou seja, são ressignificados. Um exemplo de como os objetos, sob a forma de mercadorias, passaram a ser vendidos, é apresentado de modo explícito por Hannah Arendt (1981, p. 137): com a produtividade alcançada com a Revolução Industrial, os objetos de uso "tiveram que ser tratados como se fossem bens de consumo, de sorte que uma cadeira ou uma mesa seriam consumidas tão rapidamente quanto um vestido, e um vestido quase tão rapidamente quanto o alimento". 
Claro está, portanto, que a cultura de consumo está intrinsecamente associada à Revolução Industrial, já que foi esse o acontecimento que gerou o excesso de produtos a serem vendidos, levando a outras transformações que também foram fundamentais para a constituição de um modo de vida guiado pelo consumo como, por exemplo, uma mudança profunda no comércio varejista. É o sociólogo Richard Sennett (1988) quem nos mostra que "a loja de departamentos foi uma resposta à fábrica". Segundo o autor, as primeiras lojas de departamento que surgiram primeiro em Paris (a Bon Marché, em 1852) e, logo em seguida, em Londres e Chicago, foram resultado do sistema de produção: "artigos feitos à máquina podiam ser feitos mais rapidamente e em muito maior volume do que os artigos feitos à mão" (Sennett, 1988, p. 181). A lógica contida era fixar os preços dos produtos, com uma margem de lucro menor, mas com grandes 220 volumes de vendas.

Sennett igualmente nos mostra como outros fenômenos tiveram que existir para que a estratégia das lojas de departamento - que era ter uma multidão de compradores funcionasse. Foi necessária uma revolução urbana e nos transportes para que, de fato, os compradores pudessem chegar às lojas. Daí a criação dos grands boulevards em Paris, na década de 1860, assim como a criação de sistemas de transportes em Paris e Londres por volta dessa mesma década. Em Chicago, mostra-nos o autor, também houve essa combinação entre transporte rápido e comércio varejista, especialmente após o Grande Incêndio de 1871.

Ainda que não houvesse o termo macromarketing à época - que, em marketing, designa o gerenciamento das políticas do macroambiente (cf. Dawson, 2005, p. 117) -, é possível afirmar que o que ocorria naquele momento era, justamente, uma atuação conjunta entre mercado e âmbito público, no sentido de fornecer a infraestrutura 
necessária para que a cultura de consumo efetivamente existisse. Tal reorganização se complementava no nível micro, no qual as lojas de departamentos são um exemplo perfeito do uso de técnicas de estímulo ao consumo que, até hoje, são utilizadas: a justaposição inesperada, ou seja, o critério de colocar diferentes objetos juntos, um lado do outro, a fim de suspender o caráter de uso dos mesmos e gerar um estranhamento que levaria ao desejo de possuí-lo; a decoração e o caráter de espetáculo das vitrines, nas quais um vestido feito à máquina era posto ao lado da foto de uma duquesa, sugerindo uma clara associação entre o uso do vestido e o status aristocrático que este promoveria. Enfim, técnicas que tinham por intenção fundamental revestir os objetos de significações para além de sua utilidade (cf. Sennett, 1988).

Mas toda essa reorganização do ambiente macro e micro visando um potencial consumidor não é suficiente para que ele, de fato, exista. Ainda que houvesse todo o desejo e investimento dos industriais da época em vender seus produtos feitos à máquina, e ainda que tenha havido uma série de transformações técnicas e urbanas, assim como o desenvolvimento de um novo tipo de comércio, nada disso teria resultado em uma "cultura de consumo" se não existissem pessoas dispostas a comprar. O que começou a levar as pessoas a desejarem possuir mercadorias com as quais faziam associações nunca antes vistas? Se os estímulos ao consumo promovidos pelas lojas de departamento começaram a funcionar é porque havia uma disposição psíquica para se acreditar que era possível "ser outra pessoa" apenas por usar um vestido que sugeria uma conexão com a foto da duquesa X. Na trilha desse exemplo, Richard Sennett (1988, p. 186) dá uma pista:

[...] um vestido, em 1750, não era uma questão de como a pessoa se sentia, era uma marcação, elaborada e arbitrária, 
do lugar que ela ocupava na sociedade, e quanto mais alto se estava na sociedade, mais liberdade se teria para jogar com aquele objeto, a sua aparência, de acordo com regras elaboradas e impessoais. Por volta de 1891, possuir o vestido certo, fosse ele produzido em massa e não muito bonito, leva uma mulher a sentir-se casta ou sexy, uma vez que suas roupas 'a' expressavam.

Trata-se de uma revolução nas mentalidades que é herdeira de dois acontecimentos cruciais na passagem do século XVIII para o XIX: a Revolução Francesa e a Revolução Industrial, acontecimentos que determinaram um novo momento histórico, no qual as identidades deixaram de ser definidas pelo lugar fixo e arbitrário que se ocupava na sociedade - decorrentes de uma estrutura social rigidamente definida - e passaram a ser marcadas pela mobilidade social. Isso permitiu uma "renúncia à civilidade for222 mal do Antigo Regime, em prol das relações psicológicas pretensamente espontâneas", nas palavras do psicanalista Jurandir Freire Costa (2004, p. 153). Porém, a antiga etiqueta "do decoro e da distância [...] tinha a vantagem de dizer o que era e deveria ser um 'indivíduo civilizado'. Ser civilizado significava comportar-se de modo a ter um nome, uma linhagem, uma reputação na boa sociedade". Sem esse enquadre da etiqueta e dos maneirismos da corte, o "novo mundo" - o interior - acabou gerando incertezas identitárias: "os indivíduos, quanto mais intimistas e autocentrados se tornavam, mais inseguros, intolerantes e ansiosos vinham a se comportar nas relações consigo e com os outros" (Costa, 2004, p. 153).

É nesse ponto que Costa localiza a importante contribuição do estudo de Sennett para a compreensão das raízes da cultura de consumo moderna, pois o que ele mostra é que, em um primeiro momento, foi a cultura burguesa que passou a se apropriar dos objetos como uma forma de exte- 
riorização de sentimentos e também como uma forma de localização no mundo. Os objetos de consumo eram usados para expressar um modo de vida, de crenças, de emoções que ainda estavam em processo de conformação. Mas, com isso, o "intimismo se espraiou pelo mundo dos negócios, que, por seu turno, explorou-o com vistas à maximização de lucros" (Costa, 2004, p. 155).

Portanto, se o capitalismo é um modo de produção de valor que requer necessidades sociais renovadas de mercadorias para que o ciclo de expansão do capital se perpetue, ele também precisa ser entendido como um modo de produção de mundo, um mundo que deve ser colonizado pela lógica da mercadoria. A história da produção desse mundo começa com a formação de uma cultura de consumo que ressignificou o campo das ilusões sociais desde, pelo menos, meados do século XIX. Cultura de consumo é, portanto, todo um modo de vida que foi se colando ao e ressignificando o uso dos objetos de uma época, seus valores e suas ilusões.

Pode-se afirmar, então, que a cultura do consumo se constituiu, antes de tudo, como uma cultura material, uma cultura de objetos a serem consumidos. Foi isso que Marx compreendeu em sua análise do modo de produção capitalista, a partir da segunda metade do século XIX, qual seja, o capitalismo industrial, um estágio de expansão do capital baseado na produção de coisas materiais sob a forma de mercadorias. Os exemplos dados pelo autor, em $O$ capital, são claros nesse sentido: o ferro, o linho, o trigo, a madeira, o casaco, a mesa.

Esse modelo de consumo se estendeu por todo o século XX. A emergência do estilo de vida suburbano nos Estados Unidos após a Segunda Guerra Mundial é mais um exemplo de como a cultura de consumo se reconstrói continuamente colada a uma cultura material: casas, automóveis, gasolina, estradas, centros comerciais, mas também 
geladeiras, cortinas, cortadores de grama, televisão etc. Em outras palavras, "algo mais do que a publicidade está em jogo aqui. O que é necessário é a formação de condições diárias de vida que exigem a absorção de um conjunto de certas mercadorias e serviços, a fim de se sustentar" (Harvey, 2010b, p. 91).

Em torno desse modelo, gravitam termos chaves para a compreensão do consumo como espaço de realização do valor da mercadoria: obsolescência programada, técnica existente desde o início do século XX e que corresponde a uma astúcia da produção em promover, em cada série de produto, uma diferença nos objetos que forcem a sua troca, provocando um giro mais rápido no consumo; o nascimento do crédito ao consumidor, considerado por alguns historiadores do consumo o responsável pela própria constituição da cultura de consumo (cf. Calder, 1999), o investimento na produção de uma indústria publicitária através de 224 imagens de sedução e persuasão, operante a partir das técnicas de relações públicas, dos anúncios comerciais, do merchandising, entre outras. Tais processos, que visam superar a lacuna temporal do salto mortal da mercadoria, expandir o valor pela imagem, acelerar o giro do capital pela antecipação do consumo, dão conta de um mundo de objetos como mercadorias.

Atualmente, embora a absorção do excedente de capital esteja fortemente baseada em uma cultura de consumo de objetos como mercadorias, uma ampla literatura, incluindo autores marxistas, assume que o capitalismo contemporâneo transformou-se radicalmente, não podendo mais ser considerado a partir do modelo de produção industrial analisado por Marx. Resta entender o que isso significa, de fato, e quais os impactos para a proposta deste artigo em defender uma análise do consumo como central para a compreensão do capitalismo atual. 


\section{Novos formatos, velhos e novos desafios: 0 consumo e a realização do valor entre 0 capitalismo financeiro e 0 imaterial}

Podemos colocar a noção de globalização - enquanto processo de desterritorialização e reterritorialização - dentro deste movimento paradigmático que indica o desaparecimento das divisões tradicionais que separavam os regimes de produção das formas de concorrência, a esfera real da esfera financeira, o trabalho material do trabalho imaterial. (Cocco, 1995, P. 1171)

Segundo análises contemporâneas, após os anos 1970, o capitalismo teria se transformado, entre outras adjetivações, em um capitalismo tardio, multinacional, pós-moderno, midiático, do espetáculo ou da imagem (Jameson, 1993; 1991) do signo (Baudrillard, 1995); financeiro ou "portador de juros" (Chesnais, 1998, 2005; Paulani, 2013); imaterial, do conhecimento ou cognitivo (Gorz, 2005; Virno, 2004; Thrift, 2005; Lazzarato e Negri, 2001; Hardt e Negri, 2002). Essas diferentes denominações abarcam, muitas vezes, características em comum. Por isso, para os objetivos a que este artigo se propõe, foram agrupadas em duas interpretações dominantes que também se interpenetram: capitalismo financeiro e capitalismo imaterial.

\section{O consumo no capitalismo financeiro}

A compreensão do capitalismo guiado pela lógica financeira se tornou dominante a partir das três últimas décadas do

\footnotetext{
${ }^{5}$ No artigo que foi a base para o seu livro mais contundente acerca da nova lógica do capitalismo, Postmodernism, or the cultural logic of late capitalism, Fredric Jameson também faz uso do termo capitalismo de consumo. Este termo, de fato, acaba sendo aquele que melhor define o que o autor pretende desenvolver em suas análises sobre as transformações do capitalismo: como a cultura se tornou um produto, o mercado se tornou seu próprio substituto e o pós-modernismo passou a significar "o consumo da própria produção de mercadorias como processo” (Jameson, 1991, p. 14).
} 
século XX. O economista francês François Chesnais, dizia que o mundo àquela época apresentava "uma configuração específica do capitalismo, na qual o capital portador de juros - um capital que busca fazer dinheiro sem sair da esfera financeira - está localizado no centro das relações econômicas e sociais (cf. Chesnais, 2005, p. 35). Parecia, finalmente, que a ilusão do capital tornara-se factível, ou seja, "o processo de valorização do valor que é definidor do capitalismo" passou a ser comandado pela lógica financeira, "que é rentista e curto-prazista” (Paulani, 2013, p. 16). Por essa época, o capital - com o suporte de um projeto político neoliberal já havia recuperado o controle sobre o trabalho e, diante de uma classe desempoderada, mas com baixos salários, "o problema da falta de demanda para a expansão da produção das corporações capitalistas" foi resolvido mediante a expansão da indústria de cartões de crédito e aumento do endividamento" (Harvey, 2010b, pp. 22-24).

226 Para os propósitos deste artigo, é importante destacar o quanto o sistema de crédito sempre se apoiou em bases materiais do consumo e como foi por essa via - a do consumo - que o crédito se expandiu a ponto de inverter o que antes parecia solução em problema, como atesta a crise financeira de 2008. Neste caso em particular, e a partir do exemplo norte-americano, ficou evidente o quanto a base da financeirização da riqueza era a mais material das mercadorias: o imóvel. Conforme análise apresentada por Harvey, no epicentro da crise "estava a montanha de títulos de hipoteca 'tóxicos', detidos pelos bancos ou comercializados por investidores incautos em todo o mundo. Todo mundo tinha agido como se os preços dos imóveis pudessem subir para sempre" (Harvey, 2010b, p. 10).

No rastro dessa análise, a pesquisa desenvolvida por Mariana Fix mostra quanto o "desejo da casa própria" foi uma construção cultural norte-americana, pelo menos, desde 1929, a partir de um esforço consciente de expansão 
da forma mercadoria. Foi nesse período que, segundo Fix, começou a se configurar um novo circuito de produção, circulação e consumo de moradias a partir de ações combinadas dos agentes imobiliários e do governo, como a campanha norte-americana make her happier, ainda nos anos 1920. Assim, o sistema de hipotecas desenvolvido nos anos 1930, nos Estados Unidos, foi, na verdade, a base da securitização de ativos imobiliários dos anos $1980^{6}$ (cf. Fix, 2011).

No fim da década de 1990, essa lógica foi radicalizada: de um lado, fornecendo-se crédito aos consumidores com rendimentos baixos e, sequer, com renda constante; de outro, fornecendo-se formas de crédito ao consumo para todo o tipo de produto: além do imóvel,

[...] automóveis e cortadores de grama até fácil acesso a cartões de presente de Natal na Toys 'R' Us e Wal-Mart. Todo esse endividamento era obviamente arriscado, mas isso era para ser controlado por maravilhosas inovações

financeiras de securitização que, supostamente, partilhariam o risco, criando a ilusão de que este tinha desaparecido (Harvey, 2010b, p. 24).

\footnotetext{
${ }^{6}$ Essa relação entre capitalismo e circuito imobiliário já havia sido contemplado por Marx, conforme documenta Mary Gabriel (2013) com base nos Collected Works de Marx e Engels (1975-2004). Diz ela que, ao mencionar a criação de mercados a fim de promover a circulação do capital, Marx deu particular atenção à indústria de construção civil, "na qual os construtores já não construíam sob demanda, mas operavam inteiramente como especuladores. A magnitude das construções exigia que o construtor excedesse em muito seus próprios recursos financeiros e pedisse empréstimos de capitais sob a premissa de que poderia pagar de volta quando vendesse aqueles imóveis construídos para ninguém em particular. Mas essa fórmula colocava a questão da moradia, outrora uma pedra fundamental da estabilidade social e do desenvolvimento, na mesma situação precária de outros investimentos de capitais. Como o mercado financeiro, o setor da construção então estava sujeito às quebras do sistema" (Gabriel, 2013, pp. 689-90). Mary, então, cita palavras de Marx que parecem baseadas na crise das hipotecas de 2008, mas que foram proferidas em 1885: "na melhor das hipóteses, as casas continuam inacabadas até que venham tempos melhores; na pior, as casas são vendidas em leilões pela metade do preço de custo" (Marx e Engels, 1975-2004, pp. 235-36).
} 
Tal lógica também vem sendo cada vez mais incorporada no processo atual de inserção da economia brasileira no processo mundial de acumulação. Segundo Paulani (2013), apoiada em Chesnais (1998), "essa forma de inserção é característica da etapa madura da financeirização, onde a intermediação bancária perde força, sendo substituída pelas chamadas 'finanças diretas', que têm como principais personagens os fundos de investimento e os fundos de pensão, as bolsas e os mercados secundários de títulos, os processos de securitização e os derivativos”. Esse modelo, conforme ainda analisa Paulani, assim como Bresser-Pereira e Gala (2007), leva ao aumento no consumo e endividamento dos consumidores.

O endividamento como base para o consumo, por sua vez, sempre esteve no centro da organização do capital tendo em vista a realização do valor. Como já posto, historiadores do nascimento da cultura de consumo chegam a 228 atribuir esse fato à criação do crédito ao consumidor (cf. Calder, 1999), cujo objetivo era a antecipação do desejo de realização do consumo e, fundamentalmente, o giro rápido das mercadorias, permitindo com isso a diminuição da lacuna temporal da realização do valor ${ }^{7}$. O que ocorre, hoje, é apenas uma sofisticação dos métodos de financeirização da economia que, por seu turno, tem levado a uma radicalização do processo de endividamento, visando dar conta das contradições do capital, que têm se acentuado desde a década de 1970 e, em especial, após a crise de 2008.

É sobre esse processo intensivo de endividamento que autores contemporâneos, de tradições teóricas diversas, vêm se debruçando: "capitalismo parasitário", do sociólogo Zygmunt Bauman, é uma análise dialética sobre a crise finan-

\footnotetext{
${ }^{7}$ Nesse aspecto, convém mencionar o sociólogo Georg Simmel (2002) que, na análise do dinheiro, já antevia a "tentação à imprudência", tendo em vista quão rápida circulação do dinheiro já induzia, segundo ele, as pessoas a gastarem e mudarem inclusive o seu caráter.
} 
ceira atual a partir da ideia de que o capitalismo "não pode ser simultaneamente coerente e completo: se é coerente com seus princípios, surgem problemas que não é capaz de enfrentar; se tenta resolver esses problemas, não pode fazê-lo sem cair na incoerência em relação a seus pressupostos fundamentais" (Bauman, 2010, pp. 7-8). O exemplo dado pelo autor é, justamente, a criação das hipotecas subprime, que foram vendidas à opinião pública como solução para aqueles que não tinham moradia. Entretanto, analisa Bauman, os "sem-teto" são uma "praga" que o próprio capitalismo produz. Ao sugerir resolver tal problema, o que ele acaba fazendo - e fez, neste caso - é multiplicar o número de pessoas sem casa, com o processo de retomada dos imóveis.

Foi exatamente isso que ocorreu nos Estados Unidos, levando à crise econômica de 2008. Segundo o sociólogo Wolfgang Streeck (2011), o governo Clinton intensificou ainda mais a estratégia de gestão do conflito social a partir da desregulamentação do setor financeiro que já havia se iniciado no governo Reagan. Nesse cenário, só era possível contrabalançar o aumento crescente da desigualdade, criando oportunidades novas para os cidadãos e as empresas através do processo de endividamento. Foi assim que o termo, "keynesianismo privatizado" foi cunhado para descrever a substituição do débito público pelo privado. Desse modo,

[...] ao invés de o governo tomar dinheiro emprestado para financiar a igualdade de acesso à habitação decente, ou à formação de competências de trabalho comercializáveis; dessa vez foram os cidadãos que, sob um regime de dívida baseado em uma "extrema generosidade", eram permitidos - e por vezes obrigados -, a tomar empréstimos com base em seu próprio risco, para pagar a sua educação ou para sustentar a sua ascensão para um bairro melhor (Streeck, 2011, p. 17). 
Em A fábrica do homem endividado, o sociólogo e filósofo italiano Maurizio Lazzarato (2012) centra-se na relação de endividamento que foi exacerbada pela lógica neoliberal, relacionado, de um lado, ao processo de financeirização da economia; de outro, ao processo de transferência de todo tipo de responsabilidade para o cidadão-consumidor: não apenas a dívida com o consumo de "supérfluos", mas também com saúde, educação, segurança, que se tornaram mercadorias sob o neoliberalismo. Segundo o autor, as crises financeiras fizeram emergir a figura subjetiva do homem em dívida, que ocupou o espaço outrora reservado às figuras subjetivas prometidas pelo neoliberalismo: acionistas, proprietários, empreendedores. Trata-se de uma análise sobre como o processo de financeirização da economia e o consequente endividamento de pessoas e países fazem parte da nova lógica capitalista, que é uma espécie de penhora do futuro. Se o capitalismo, como vimos, é uma persistente aposta

230 no futuro, haja vista o processo de realização do valor e o empurrar constante das contradições, o ponto de chegada seria, então, esse processo de tomada, de antecipação violenta e predatória do tempo futuro.

\section{O consumo no capitalismo imaterial}

A segunda denominação que o capitalismo contemporâneo incorpora é a do imaterial, que é mais abrangente, pois é capaz de agrupar uma vasta interpretação sobre as transformações do capitalismo a partir dos anos 1970, englobando inclusive o processo de financeirização da economia. Isso porque o ponto fundamental que define esse tipo de capitalismo é a proposição da centralidade do trabalho imaterial, aquele que resulta da revolução informacional e que tem no saber sua principal força de produção (cf. Lazzarato e Negri, 2001; Gorz, 2005; Thrift, 2005; Virno, 2004; Hardt e Negri, 2002).

Segundo Nigel Thrift (2005), para compreendermos a lógica desse tipo novo de capitalismo, que está constan- 
temente em movimento, que incorpora o saber e a inovação cada vez mais rapidamente e é mais adaptável que os modelos anteriores, é necessário entendermos como a revolução da informação que está em sua base foi combinada a três outros desenvolvimentos capitalistas: (1) novas formas de produção de mercadoria, envolvendo a produção para o consumo, bem como a valorização das marcas, patentes e finanças; (2) novas formas de tempo e espaço de produção, com o desenvolvimento do conhecimento lógico posto a serviço de novos arranjos espaciais com redução de estoques, uma engenharia de produção e consumo mais rápido, monitoramento contínuo, enfim, formas de gestão do conhecimento, portanto, de controle; e (3) um novo tipo de discurso, ao qual o autor chama de "circuito cultural do capitalismo", a partir dos usos e significados da cultura.

Esses três desenvolvimentos estão profundamente imbricados. Por exemplo, os novos usos da palavra cultura, que promovem o "circuito cultural do capitalismo", são fundamentais no processo de valorização das marcas, patentes e finanças e trazem consequências que nos interessa mais diretamente: tornam o consumo de imagens, serviços ou experiências algo mais central do que o consumo material.

Tendo em vista a dinâmica própria do capital discutida anteriormente, a entrada em cena das novas tecnologias se deu pela necessária aceleração no salto da lacuna temporal para a realização do valor e sua expansão pelo consumo. Isso levou a uma "fuga para frente" (cf. Buckminster-Fuller, 1981), com o consumo buscando anteceder a produção: de um lado lançando-se mão de pesquisas de mercado focada em antecipar tendências culturais que pudessem ser convertidas em mercadorias; de outro, garantindo-se uma produção just-in-time. Desse modo, expandiu-se a área de serviços e multiplicaram-se, também, a oferta de novas mercadorias, que começaram a ser vendidas mais por seu valor de "imagem" (a marca) 
do que pelo apelo aos seus atributos físicos ${ }^{8}$. Veja-se que, nesse aspecto, o consumo do imaterial se coaduna com a questão financeira, já que as marcas publicitárias e seu valor simbólico, de imagem - passaram a fazer parte do jogo de valorização fictícia do capital das empresas (cf. Gorz, 2005). Exemplo disso é o ranking das marcas mais valiosas do mundo, cujo valor de imagem é maior que o ativo físico que suas corporações detêm.

Assim, se o saber se tornou a principal força produtiva no estágio do capitalismo imaterial, a cultura se tornou sua principal mercadoria. Ou seja, o capitalismo imaterial é o que produz a informação e o conteúdo cultural da mercadoria. Um exemplo concreto, dado por David Harvey (2003), ajuda na compreensão desse processo. Buscando entender como se comercializa cultura como mercadoria, o autor mostra como se deu a transformação da ideia de "rendimento monopólico" na passagem do capitalismo analisa232 do por Marx para o capitalismo contemporâneo. Lembra que "o poder monopólico da propriedade privada é tanto o ponto de partida como o de chegada de toda atividade capitalista" (Harvey, 2003, p. 146). E mostra como as mudanças nas condições de transporte e de comunicação alteram radicalmente a lógica dos monopólios no capitalismo atual. Um dos exemplos que o autor usa é o da produção de vinho. Retoma Marx e lembra que, para o autor, somente o vinhedo que produzia um vinho de qualidade extraordinária - em função da qualidade da terra e do clima - poderia ser vendido a preço monopólico. Mostra como os países europeus, em especial a França, lançaram mão desse artifício para "preservar rendimentos monopólicos ao insistir nas virtudes únicas da terra, do clima e da tradição (aglo-

\footnotetext{
8 Trata-se, como mostrou Fredric Jameson (2001), de uma imbricação entre a economia e a cultura: enquanto a economia busca transformar qualquer produção cultural em uma mercadoria, a cultura passa a dar lastro simbólico a qualquer objeto banal sob o signo da marca.
} 
merados sob a palavra francesa terroir) e a distinção de seu produto certificado por um nome" (Harvey, 2003, p. 150). Através de poderosos controles institucionais, a França chegou a obter o direito único de usar termos como chateau, domaine, champagne, chablis, sauterne, entre outros.

Surge, porém, o norte-americano Robert Parker e sua publicação independente, o Wine advocate, cuja função é qualificar e classificar (por pontos) os vinhos segundo o seu sabor, sem se remeter a questões históricas ou culturais. Parker mudou o discurso do "terroir" e da tradição para outra forma discursiva, tais como a importância em definir um vinho por seu "sabor de pêssego e ameixa, com uma lembrança de tomilho e groselha”. Isso prova, diz Harvey, que "as alegações monopólicas são tanto um efeito do discurso e um resultado da luta como reflexo das qualidades dos produtos". Essa mudança na qualificação dos vinhos seria, portanto, a prova da mudança na forma de competição trazida pela globalização e o comércio crescente de vinhos em linhas padronizadas (Harvey, 2003, pp. 151-52).

Assim, com a perda da proteção monopólica garantida pelos recursos naturais de espaço e localização, assim como com o processo de desregulamentação dos mercados, um dos caminhos buscados pelo capital foi garantir "os direitos monopólicos da propriedade privada por meio de leis comerciais internacionais que regulamentem todo o comércio global. [Por isso], as patentes e os chamados 'direitos de propriedade intelectual' tornaram-se um campo importante de luta" (Harvey, 2003, p. 148). Pode-se dizer o mesmo dos rendimentos monopólicos advindos das grandes marcas comerciais (Fontenelle, 2002). Essa questão coloca o consumo no centro da batalha do capitalismo imaterial, pois o desafio está em "transformar a invenção em mercadoria, e pô-la no mercado como um produto de marca patenteada" (Gorz, 2005, p. 42). 
Esse processo é também fundamental no mundo da produção e do consumo virtuais. A análise efetuada pela socióloga Diaz-Isenrath (2008) sobre o processo de criação do Google é exemplar. Contrapondo um artigo acadêmico escrito em 1998 por dois doutorandos em engenharia de computação, da Universidade de Stanford - Lawrence Page e Serge Brin, fundadores do Google -, ao pedido de registro da empresa por eles criada à Comissão de Valores e Bolsas dos Estados Unidos, em 2004, a autora demonstra de que maneira o conhecimento científico foi sendo apropriado pela lógica do mercado.

A partir de uma longa descrição do artigo escrito pelos ainda estudantes, Diaz-Isenrath mostra que Page e Brin narram como se deu o completo envolvimento de colegas, cientistas e técnicos do campo acadêmico no desenvolvimento do projeto, ao mesmo tempo que afirmam como seu artigo seria uma primeira descrição pública da criação desse tipo de fer234 ramenta, qual seja, uma ferramenta de busca. Quando entra em cena o pedido de registro, seis anos depois, o documento “dirige-se aos investidores. Essa descrição, que se publica em 2004 (a empresa passava a ser nesse momento uma companhia aberta), não diz respeito à 'anatomia do sistema' ou ao algoritmo, mas à 'missão da empresa', ao 'modelo de negócio' e ao "plano de ação”" (Diaz-Isenrath, 2008, p. 52).

Enquanto, no artigo de 1998, Page e Brin justificavam que projetaram tal sistema de busca a fim de auxiliar outros colegas pesquisadores e estudantes para "entrar rapidamente, processar grandes porções da web e produzir resultados ou experimentos interessantes" (Page e Brin, 1998, p. 109) ${ }^{9}$, o pedido de registro, apenas seis anos depois, deixa claro que "a busca e a experimentação não se restringem à 'pesquisa' em sentido estrito” (Diaz-Isenrath, 2008, p. 52).

\footnotetext{
${ }^{9}$ Ver "The anatomy of a large-scale hypertextual Web search engine". Disponível em: <http://www.sciencedirect.com/science/article/pii/S016975529800110X>. Acesso em: 2 jul. 2014.
} 
Os fatores de risco envolvidos na relação entre estrutura corporativa e sistema técnico são também exaustivamente descritos no documento em questão.

A marca Google tornou-se uma das mais valiosas do mundo e seu processo de produção de valor ocorre pelo consumo de informações, a partir do acesso de usuários ao seu site. Nesse aspecto, o consumo aparece relacionado ao cerne do capitalismo como produção do valor e ganha um estatuto próprio: deixa de ser visto, apenas, como o que realiza o valor no capitalismo, mas também como o que pode produzir valor. Não por acaso, é no espaço da internet, especialmente da Web 2.0, que os sociólogos Ritzer, Dean e Jungerson (2012) analisam o embaralhamento das fronteiras entre trabalho e consumo, argumentando que muitos dos grandes sites como o Google, que são sabidamente grandes organizações capitalistas, incorporam parte do trabalho não pago de seus usuários. Seriam os usuários produtores ou consumidores? É justamente isso que fica embaralhado. Com relação especificamente ao Google, os autores demonstram como o usuário se sente privilegiado por ter direito a usar muitos serviços não pagos, como o Google map, Google translator, entre outros. Porém, os autores lembram que o Google tira seu principal rendimento das consultas que seus usuários fazem às diferentes páginas de empresas, que, por sua vez, pagam ao Google para estarem em seu site, de preferência, no topo da lista.

$\mathrm{E}$ aqui, entramos no debate mais amplo que envolve a questão do imaterial: o da apropriação do saber ou do general intellect, termo originalmente cunhado por Marx. Na interpretação do sociólogo Paolo Virno,

[...] o general intellect é o saber social tornado principal força produtiva; é o conjunto de paradigmas epistêmicos, de linguagens artificiais, de constelações conceituais que dão nervura à comunicação social e à forma de vida. $\mathrm{O}$ general intellect distingue-se das "abstrações reais" típicas da 
modernidade, todas ancoradas no princípio de equivalência. "Abstração real" é, sobretudo, o dinheiro, que representa a comensurabilidade dos trabalhos, dos produtos, dos sujeitos. Pois bem, o general intellect nada tem a ver com o princípio de equivalência. Os modelos do saber social não são unidade de medida, mas constituem sim o pressuposto para possibilidades operativas heterogêneas. Os códigos e paradigmas técnico-científicos se apresentam como "força produtiva imediata”, isto é, como princípios construtivos. Não se equiparam a nada, mas fazem às vezes de premissas para todo gênero de ações (Virno, 2004, pp. 54-55; grifos meus).

Giuseppe Cocco (1995, p.1173) lembra que "é unicamente no trabalho imaterial, figura historicamente determinada do general intellect (do saber social geral) que é impossível separar tempo de trabalho do tempo de reprodução. Mas a esse nível, as figuras específicas dos trabalhadores 236 aparecem ainda de forma muito abstrata e indeterminada”. Nesse contexto em que trabalho e consumo se embaralham, assim como produção e realização do valor, o espaço virtual se imbrica cada vez mais com a materialidade da vida vivida, com a nossa localização no mundo e do mundo. $\mathrm{Na}$ interdependência da nossa vida material com o mundo virtual, reordena-se também a lógica da ilusão social a partir do consumo que predominou ao longo do século XX. A produção do novo trabalhador-consumidor deve obedecer muito mais à lógica subjetiva do consumidor do que do produtor. Nesse contexto, o consumo ganha outra dimensão ainda não explorada.

\section{$* * *$}

Um resgate histórico acerca dos estudos do consumo no campo da teoria social permitiu que pudéssemos vislumbrar, pelo menos, duas abordagens distintas sobre o 
tema do consumo: a que propõe sua análise como processo cultural autônomo, não derivado inequivocamente da produção capitalista; e a que surge no contexto da teoria marxista, que não pensa o consumo como espaço de emancipação, haja vista tê-lo identificado como lugar da ilusão. Vimos em Žižek que, como espaço da ilusão, o consumo diz a verdade do capital: a busca da sua autorreprodução infinita. Vimos também, a partir da teoria marxiana, que o consumo é o espaço no qual, de fato, o valor se realiza. Ele é gerado na produção, mas só se realiza no momento do consumo.

Essa centralidade do consumo pôde ser constatada nos formatos contemporâneos do capitalismo, analisados aqui pela perspectiva do capitalismo financeiro e do imaterial. Neste último, compreendemos como tem se dado um embaralhamento nas relações entre trabalho e consumo e, portanto, entre produção e realização do valor.

Conclui-se, portanto, que o consumo não aparece mais apenas como central na determinação do valor, em sua imbricação ao processo mesmo de produção. Ele se torna central na medida em que formata a subjetividade dessa nova forma de produzir e consumir. Assim, da mesma maneira que se evidencia uma batalha em curso no processo de mercantilização da produção social, do general intellect, via marcas, patentes, circuitos comunicativos e novos direitos de rendimentos monopólicos, abre-se como campo político o necessário controle subjetivo sobre o consumidor. Essa é a perspectiva que a análise aqui empreendida procurou abrir e espera-se que, com ela, se possa contribuir para preencher um gap nos estudos sobre a relação entre consumo e capitalismo na contemporaneidade.

\section{Isleide Arruda Fontenelle}

é professora dos cursos de graduação e pós-graduação da FGV-SP. 


\section{Bibliografia}

ARENDT, H. 1981. A condição humana. Forense Universitária.

BAUDRILLARD, J. 1995 [1972]. Para uma crítica da economia política do signo. Lisboa: Edições 70.

1998 [1970]. The consumer society: myths and structures. London: Sage.

BAUMAN, Z. 2010. Capitalismo parasitário. Rio de Janeiro, Zahar.

BOLTANSKI, L.; CHIAPELLO, E. 2009. O novo espírito do capitalismo. São

Paulo: Martins Fontes.

BRESSER-PEREIRA, L. C.; GALA, P. 2007. "Por que a poupança externa não promove o crescimento". Revista de Economia Política, v. 27, n. 1, pp. 3-19, jan.

BUCKMINSTER FULLER, R. 1981. Critical path. [s.1.], USA: St. Martin Press.

CALDER, L. 1999. Financing the American dream: a cultural history of consumer credit. Princeton: Princeton University Press.

CAMPBELL, C. 2001. A ética romântica e o espírito do consumismo moderno. Rio de Janeiro: Rocco.

CHESNAIS, F. 1998. "Introdução à mundialização financeira". In:

CHESNAIS, F. (org.). A mundialização financeira. São Paulo: Xamã. 2005. A finança mundializada. São Paulo: Boitempo.

COCCO, G. 1995. "A produção e a cidade no pós-fordismo: as noções de trabalho imaterial e de 'bacia' de trabalho imaterial”. In:

ENCONTROS NACIONAIS DA ANPUR, v. 6. Disponível em: < http:/ / www.anpur.org.br/revista/rbeur/index.php/anais/article/view/1672>. Acesso em: 29 jul. 2014.

COSTA, J. F. 2004. O vestígio e a aura. Rio de Janeiro: Garamond.

DAWSON, M. 2005. The consumer trap: big business marketing in American life. Chicago: University of Illinois Press.

DIAZ-ISENRATH, M. C. 2008. Máquinas de pesquisa: o estatuto do saber no capitalismo informacional. Tese de doutorado em Ciências Sociais. Universidade Estadual de Campinas.

FEATHERSTONE, M. 1987. "Lifestyle and consumer culture". Theory, Culture and Society, v. 4, n. 1, pp. 55-70. 1990. Consumer culture and postmodernism. London: Sage.

FIX, M. D. A. B. 2011. Financeirização e transformações recentes no circuito imobiliário no Brasil. Tese de doutorado. Instituto de Economia da Universidade Estadual de Campinas. Disponível em: < bibliotecadigital. unicamp.br>.

FONTENELLE, I. 2002. O nome da marca: Mcdonald's, fetichismo e cultura descartável. São Paulo: Boitempo. 
FRANK, T. 1997. The conquest of cool: business culture, counterculture and the rise of hip consumerism. Chicago: The University of Chicago Press. GABRIEL, M. 2013. Amor e capital: a saga familiar de Karl Marx e a história de uma revolução. Rio de Janeiro: Zahar.

GORZ, A. 2005. O imaterial: conhecimento, valor e capital. São Paulo: Annablume.

HARDT, M.; NEGRI, A. 2002. Império. Buenos Aires: Paidós.

HARVEY, D. 2003. "A arte de lucrar: globalização, monopólio e exploração da cultura”. In: MORAES, D. (org.). Por uma outra comunicação. Rio de Janeiro: Record. 2010a. Para entender o capital. Livro I. São Paulo: Boitempo. . 2010b. The enigma of capital: and the crises of capitalism. London: Profile.

HOBSBAWM, E. J. 2006. A era das revoluções. Vol. 4. Paz e Terra.

JAMESON, F. 1991. Postmodernism, or the cultural logic of late capitalism. Durham, USA: Duke University Press. . 1993. "O pós-modernismo e a sociedade de consumo". In:

KAPLAN, E. A. O mal estar no pós-modernismo. Rio de Janeiro: Jorge Zahar. pp. 25-44. 2001. A cultura do dinheiro: ensaios sobre a globalização. Petrópolis: Vozes.

LAZZARATO, M. 2006. As revoluções do capitalismo. Rio de Janeiro: Civilização Brasileira. . 2012. The making of the indebted man: an essay on the neoliberal condition. Los Angeles: Semiotext(e).

LAZZARATO, M.; NEGRI, A. 2001. Trabalho imaterial: formas de vida e produção de subjetividade. Rio de Janeiro: DP\&A.

LIPOVETSKY, G. 2007. A felicidade paradoxal: ensaio sobre a sociedade de hiperconsumo. São Paulo: Cia. das Letras.

MARX, Karl. 1992. Capital. Vol. 1. London: Penguin.

MARX, K.; ENGELS, F. 1975-2004. Collected works. Moscow, London, New York: Progress Publishers, International Publishers, and Lawrence \& Wishart. 50v.

McKENDRICK, N.; BREWER, J.; PLUMB, J. 1983. The birth of a consumer society. London: Hutchinson.

MILLER, D. 2013. Trecos, troços e coisas: estudos antropológicos sobre a cultura material. Trad. Renato Aguiar. Rio de Janeiro: Jorge Zahar Ed.

NEGRI, A. 1989. The politics of subversion: a manifesto for the twenty-first century. Cambridge: Polity Press. 
PAULANI, L. 2013. "Acumulação sistêmica, poupança externa e rentismo: observações sobre o caso brasileiro”. Estudos Avançados, v. 27, n. 77, pp. 237-64.

RITZER, G.; DEAN, P.; JURGENSON, N. 2012. "The coming of age of the prosumer". American Behavioral Scientist, v. 56, n. 4, pp. 379-98.

SENNETT, R. 1988. O declínio do homem público: as tiranias da intimidade. 4a. reimpr. São Paulo: Cia. das Letras.

SIMMEL, G. 2002. Filosofia do dinheiro. João Pessoa, PB: GREM.

SLATER, D. 1997. Consumer culture and modernity. Cambridge: Polity Press. STREECK, W. 2011. "The crises of democratic capitalism". New Left Review, v. 71, n. 5 .

THRIFT, N. 2005. Knowing capitalism. London: Sage.

VIRNO, P. 2004. A grammar of the multitude: for an analysis of contemporary forms of life. Cambridge: MIT Press.

WEBER, M. 2004. A ética protestante e o espirito do capitalismo. São Paulo: Companhia das Letras.

ŽIŽEK, S. 2008 [2006]. A visão em paralaxe. Trad. Maria B. Medina. São Paulo: Boitempo. 


\section{O ESTATUTO DO CONSUMO NA COMPREENSÃO DA LÓGICA E DAS MUTAÇÕES DO CAPITALISMO}

\section{ISLEIDE ARRUDA FONTENELLE}

Resumo: Embora o consumo se apresente como fundamental para a compreensão do modo de funcionamento do capitalismo contemporâneo, não é assim que ele tem sido abordado do ponto de vista da teoria social. É certo que já há um campo de estudos sobre o consumo advindo da sociologia, da antropologia e dos estudos culturais, porém, são estudos que focam mais nos modos de vida, na formação cultural, nos significados, normas e valores associados aos usos das mercadorias, do que propriamente no papel central que o consumo tem na realização do valor para o capital. Este artigo pretende contribuir para reverter esse gap ao propor um retorno à abordagem marxista acerca do lugar do consumo no processo de expansão do valor. Assumindo a posição central que o consumo tem para a realização do capital, e partindo da análise dialética do capitalismo como movimento e contradição, o artigo busca elucidar as principais mutações na cultura de consumo que ocorreram a partir do final da década de 1970, culminando com as transformações oriundas da terceira revolução tecnológica - a informática. Propõe que as duas principais formas que assumiu o capitalismo em fins do século XX - o financeiro e o imaterial - operam fundamentalmente a partir do consumo; assim como revelam as mutações e as contradições do capitalismo na contemporaneidade.

Palavras-chave: Consumo; Cultura de Consumo; Valor; Capitalismo Financeiro; Capitalismo Imaterial.

\section{THE CONSUMPTION STATUTE IN UNDERSTANDING THE LOGIC AND MUTATIONS IN CAPITALISIM}

Abstract: Although consumption is fundamental for understanding the way contemporary capitalism functions, this is not the way 
it has been dealt with from the viewpoint of social theory. There is undoubtedly already a field of studies on consumption that derives from sociology, anthropology and culture studies, but such studies focus more on ways of life, on cultural formation, and on the meanings, rules and values associated with the use of goods than on the central role that consumption plays in the realization of value for capital. This article intends to help close this gap by proposing a return to the Marxist approach to the place of consumption in the value expansion process. Assuming the central position that consumption plays in realizing capital, and based on a dialectic analysis of capitalism as movement and contradiction, the article seeks to elucidate the main mutations in consumption culture that occurred as from the end of the 1970s, culminating in the transformations arising from the third technological revolution - informatics. It proposes that the two main forms that capitalism assumed at the end of the 20th century - financial and immaterial - operate fundamentally as a result of consumption, and reveal the mutations and contradictions of capitalism in contemporary life.

Keywords: Consumption; Consumption Culture; Value; Financial Capitalism; Immaterial Capitalism. 